\title{
RESEARCH STUDY ON COMMUNICATIVE COMPETENCE FEATURES OF SOCIAL SPHERE SPECIALISTS
}

\author{
Aleksandra S. Shcheglova ${ }^{1}$, Tatyana E. Demidova ${ }^{2}$, Anna. G. Akhtyan ${ }^{3 *}$, Nataliya A. Bereza ${ }^{4}$, Alfiya A. \\ Salkhenova ${ }^{5}$ \\ ${ }^{1,2,3 *, 4}$ Russian State Social University, Moscow, Russia; ${ }^{5}$ Peoples’ Friendship University of Russia (RUDN University), \\ Moscow, Russia. \\ Email: *ahtyananna@mail.ru
}

Article History: Received on $7^{\text {th }}$ May 2020, Revised on $24^{\text {th }}$ June 2020, Published on $13^{\text {th }}$ July 2020

\section{Abstract}

Purpose of the study: To study the ways to increase the communicative competence of social sphere specialists, aimed at the formation of professional and personal qualities, communicative skills, and development of professional interest and success.

Methodology: Some theoretical and empirical research methods are used: analysis of publications in social work, normative documentation on the research issue; diagnostic methods: questioning, testing, interviews; experimental methods: ascertaining, forming, and control stages of the experiment; stating, forming and control stages of the experiment; methods of statistical processing of research results.

Main Findings: The main results of the study showed that the modern practice of successful organization of social service activities requires a thoughtful approach. The head, together with the full-time psychologist, should monitor the communicative competence of the specialists working at this service and timely organize the work to overcome the manifestations of professional burnout of specialists and prevent their professional deformation. The significance of the influence of active teaching methods on interpersonal communication has allowed us to develop and test several practically effective teaching methods that increase the effectiveness of interaction with others in professional communication.

Applications of this study: This study reveals the possibilities of improving the communicative competence of the specialists working at social service departments in modern conditions of systematic emotional overload when performing their professional duties. This theme is quite relevant for the activities of any service within "person to person" interaction, especially a social one, having its specifics and directed at helping a person facing a social problem.

Novelty/Originality of this study: The novelty of this study is in justifying the need for organizing activities to improve the communicative competence of social service specialists using modern socio-psychological developments. In the modern practice of holding social work, this component is often overlooked, which subsequently leads to frequent conflicts among social service employees and recipients of social services, a gradual loss of interest in the work performed, and, as a result, its indifferent fulfilment.

Keywords: Social Work, Communicative Competence, Psychological Culture, Professional Burnout, Professional Deformation.

\section{INTRODUCTION}

One of the main components of the professional competence of a social work specialist is his/her success in professional and personal communication. As a rule, clients of social workers are citizens who are in an unstable social situation. As a result, they are not always emotionally balanced and are unlikely to maintain and establish positive social contacts.

The specifics of social work, according to E. I. Kholostovoy and L. I. Kononova (2019), consists in the fact that "when solving the problems that people are facing doing it, it directly or indirectly affects all forms and types of social relations and people's activities, all aspects of social life. The identification and solution of these problems are carried out, first of all, by establishing and maintaining contacts with the representatives of state services, public organizations and associations, citizens and social groups (clients) who need help, protection, support, which requires, in turn, high development social workers' communicative abilities" (p. 43).

Therefore, the specialist assumes both the emotional burden and responsibility for building positive social contacts with the client himself/herself and his/her closest people. This style of behavior inevitably leads to emotional burnout and the professional deformation of specialists.

The study of the communicative competence features of social specialists is an essential aim of organizing their successful social communication. In the modern practice of socio-psychological training for the formation of professional competence of specialists in the social sphere, the developments of Russian psychologists should be actively used. 


\section{LITERATURE REVIEW}

The problems of studying the features of the communicative competence of social sphere specialists refer to the related field of scientific knowledge, including the issues of communication psychology, conflicts, and methods of active social and psychological training, as well as the competences of social work specialists. These studies are complex, interdisciplinary in nature, therefore scientific research in this area is currently being conducted in a wide range of directions all over the world (Aulwin, 1985; Huber, 1990; McKee, 2009; Harris et al., 2015; Milanovic, 2017; Chigisheva et al., 2016; Garanina et al., 2017; Draskovic et al., 2017; Chigisheva et al., 2017; Tarman\&Chigisheva, 2017; Tilbury et al., 2017; Chigisheva, 2018; Gorlova et al., 2019; Zamiralova et al., 2019; Sadzaglishvili et al., 2020).

From the point of development of social work theory and competence of social work specialists, it is necessary to focus on the research of the following scientists: L. Bryant and C. Williams (2020), M. B. Negahban (2020), V. Taube and C. Bördlein (2020), T. E. Wilson (2020), A. M. Egorychev and colleagues (2018), P. D. Pavlenok (2017), M. V. Firsov, and E. G. Studenova (2016), J.W. Anastas (2014), J. S. Brekke (2014), E. I. Holostova (2007).

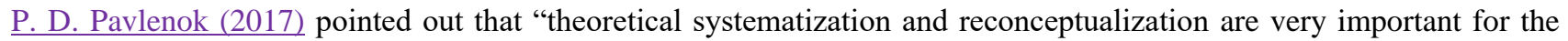
understanding of the process of social work management, training of social workers, determining their professional, spiritual and moral qualities, which ultimately affect the effectiveness of social work" (p. 37).

Firsov M. V. and Studenova E. G. (2016) determines that "the classification of social work technologies is based on the concepts of the relationship between the person and the environment, where environmental features and personal biopsycho-social factors influence human behavior in the society and his/her social activity, that can lead to a "difficult life situation" complicating the bio-psycho-social functioning of the person" (p. 13).

E. I. Holostova (2007) noted that "the structure of social work as science is determined not only by the relation of people to each other but also by the relation of people to the ideas, knowledge; interconnections of knowledge from various fields and technologies of social work" (p. 77).

The problems of social work management and social management are reflected in the works of E. I. Komarova and A. I. Voitenko (2001). They defined the functions, structure, and methods of social work management, social projects, planning, and regional models, management culture, and the effectiveness of social work. T. Knoop and T. Meyer (2020), G. P. Medvedeva (2018), R. Finzi-Dottan and M. B. Kormosh (2016), L. V. Topchy (2015), A. Caras and A.

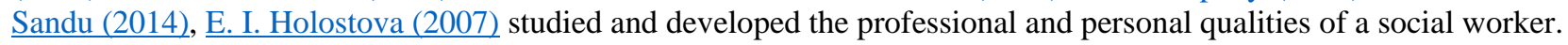

L. V. Topchy (2015) noted that "the theory of social work is that "magic glass" through the prism of which a professional social worker continuously learns the essence of social processes and problems, especially of the person himself/herself, characteristics of his/her client, degree of client`s adaptation to the social changes in the society and immediate environment, determines the potential of people in difficult life situations, finds necessary solutions, predicts the effectiveness of various methods and special techniques of social work" (p. 102).

G. P. Medvedeva (2018), in her textbook "Philosophy of Social Work", showed that "a person is the main element of social work, its object, and subject, goal, and result. At the same time, human studies in various scientific disciplines of social work are limited only to the study of man as an object and subject in the system of professional social work. The fact that a person is simultaneously a member of the society, various groups and communities are practically not taken into account, just as the role of a person who does not take part in the professional social work is not taken into account" (p. 88).

Z. P. Zamaraeva and L. I. Starovojtova (2019) noted that "in the process of forming professional competence, sociallyoriented professional subjectivity is of great importance. Its content and technological support imply, on the one hand, targeted professional activity with social protection facilities that have different levels of resource potentials (low, medium, high) to restore lost, partially lost or not acquired during socialization skills and abilities to perform social functions and roles in the modern society, on the other hand, the updating of special knowledge and skills to conduct a level assessment of resource potentials and the selection of adequate resource technologies, the formation of the necessary conditions for their implementation".

K. D. Zanina and A. G. Akhtyan (2018) emphasizes that the modern world is in continuous innovative development, covering all spheres of society, including socio-cultural. The study of personality typology in this context is becoming increasingly relevant in connection with the ability to predict the formation of innovative thinking. Every modern person every day repeatedly interacts with both individuals and groups of people, inevitably encountering various types of human character and behavior. There is a noticeable jump in the interest to the problems of social interactions considered in the field of personality typology and peculiarities of social work (van den Heuvel et al., 1989; Firsov\&Studenova, 2016; Santos et al., 2020; Straussner\&Senreich, 2020).

The analysis of scientific literature showed that the study of the communicative competence features of specialists in the social sphere is an essential and actively researched area of modern science. 


\section{RESEARCH METHODOLOGICAL FRAMEWORK}

The methodology of this article is represented by theoretical and practical developments in the field of communicative competence in social work. As part of this study, the actual activities of the "Center for Medical and Sociological Research" of Saratov are determined. This center consists of three departments:

- Psychological department that provides advisory and educational assistance to the citizens of different ages and social status as well as correctional and developmental work with children having developmental disabilities;

- Correctional department, carrying out correctional and rehabilitation work with various categories of citizens;

- Medical department that implements medical support for the educational, correctional, and rehabilitation work of the center.

Each of the departments took part in the study.

At the first stage, psychological testing was conducted to identify employees who were dissatisfied with their relationships with people and experienced particular difficulties in communication.

In the second stage, based on the test results, a group of employees experiencing communicative difficulties in their professional activities was selected to participate in the social and psychological training (SPT).

In the third stage, the evaluation of the effectiveness of the SPT program was carried out.

The article aims to study the ways to increase the communicative competence of social specialists, aimed at the formation of professional and personal qualities, communication skills of the specialist, development of the interest in the chosen profession, and success in professional activity. This study reveals the possibilities for improving the communicative competence of social service specialists in modern conditions of systematic emotional overload within the performance of their professional duties. Timely organization of diagnostics and correction of the emotional and mental mood of specialists gives a positive result, increases the success in fulfilling professional tasks, and brings satisfaction from work performed.

The following research tasks were identified:

- To analyze theoretical approaches to the study of communicativeness as a professionally significant quality of a social worker;

- To find out the essence of social work as a professional activity;

- To study socio-psychological characteristics of the social worker personality;

- To explore socio-psychological features of the communicative activities of social workers;

- To develop a program of social and psychological training (SPT) on improving the communicative activity of social workers allowing to improve the quality of social services for citizens;

- To analyze the results obtained after the SPT.

To solve the assigned tasks, several theoretical and empirical research methods were used:

- Analysis of philosophical, psychological, pedagogical, acmeological, sociological, methodical literature, some publications in social work, normative documentation on the research issue;

- Diagnostic methods: questioning, testing, interviews;

- Experimental methods: ascertaining, forming, and control stages of the experiment;

- Stating, forming and control stages of the experiment;

- Methods of statistical processing of research results.

\section{RESULTS AND DISCUSSION}

\section{Research base}

Communicative competence is one of the fundamental characteristics of professional competence and professional training of specialists in social work. The difficult current socio-economic situation in the country, the specifics of the Russian system of social protection, and remuneration, the desire of service recipients to quickly and effectively solve their problems results in the increasing emotional burden on the social specialist. In this regard, one of the main tasks of the heads of social services is to monitor the socio-psychological state of their employees. Thus, regular, systematic work on the protection of the socio-psychological state of the employees guarantees a successful professional solution of all the production tasks of this service. 
In this regard, the experience of studying the ways to improve the professional competence of employees at the "Center for Medical and Sociological Research" in Saratov in November 2018 is of great interest. It should be noted that the staff includes 30 people, 26 of who are women, and 4 are men aged 32-51 years. All employees, except for the head of the center and security and accounting personnel, were involved in the study. To study socio-psychological characteristics of the communicative activities of social workers, as well as the ways to improve its quality, the "Center for Medical and Sociological Research" conducted the research focused on the socio-psychological characteristics of the communicative activities of workers in their center.

\section{Research progress and its methods}

At the first stage, psychological testing was conducted to identify employees who were dissatisfied with their relationships with people and experiencing particular difficulties in communication. For these purposes, the following methods were used:

1) Standardized self-report on the features of interpersonal communication by I.E. Strelkova (1967). The self-report contains 16 questions. The technique reveals the following parameters of interpersonal communication:

- Satisfaction - dissatisfaction with one's relationship with others;

- With what categories of persons and to what extent this satisfaction is manifested;

- Presence of difficulties of a procedural and dynamic nature in the process of communication;

- Correspondence of existing relations with people in relation to others;

- Ability to effectively build relationships with other people;

- Attitude from others according to the criterion of understanding - misunderstanding;

- Confidence - uncertainty in relationships with people;

- Subjective assessment of the causes of difficulties in communication (in oneself - in a partner).

2) The methodology of "Communicative and organizational inclinations" by V. V. Sinyavsky, V. A. Fedoroshina (COI) (described in Rogov, 1999).

According to the results of this technique, it becomes possible to identify the qualitative characteristics of the communicative and organizational inclinations of the testees. Communicative and organizational abilities in the professions that in their content are associated with the active interaction of a person with other people act as pivotal, as their lack cannot ensure success in work. The main content of the workers activities in such professions is associated with team leadership, training, education as well as cultural, educational, and consumer services.

3) The study of the level of empathic tendencies (Egorychev et al., 2019).

A popular methodology for studying the level of empathic tendencies developed by Kazan psychologist I. M. Yusupov was used to study such a personal quality as empathy understood as an ability to voluntary emotional responsiveness to

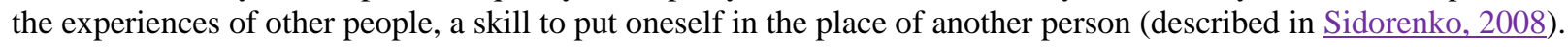

Empathy makes human behavior socially determined, contributing to the balance of interpersonal relationships. The ability of a person to empathy is a crucial factor for success in those activities that require living in the world of the communication partner. This is especially important when it comes to social work.

This technique allows determining the level of empathy development (very high, high, normal, low, and very low).

In the second stage, based on the test results, a group of employees experiencing communicative difficulties in their professional activities was selected to participate in the SPT training.

In the third stage, the evaluation of the SPT program's effectiveness was carried out.

\section{Analysis and interpretation of research results}

The first stage of our research was to diagnose the level of development of empathic trends among the center employees (see Table 1).

Table 1: The level of Development of Empathic Trends among Employees of the Center

\begin{tabular}{lll}
\hline №/code & Points & Level \\
\hline 1 & 74 & High \\
\hline 2 & 12 & Low \\
\hline 3 & 60 & Normal \\
\hline 4 & 62 & Normal \\
\hline 5 & 56 & Normal \\
\hline
\end{tabular}




\begin{tabular}{lll}
\hline 6 & 65 & High \\
\hline 7 & 58 & Normal \\
\hline 8 & 60 & Normal \\
\hline 9 & 21 & Low \\
\hline 10 & 44 & Normal \\
\hline 11 & 58 & Normal \\
\hline 12 & 68 & High \\
\hline 13 & 74 & High \\
\hline 14 & 40 & Normal \\
\hline 15 & 69 & High \\
\hline 16 & 47 & Normal \\
\hline 17 & 30 & Low \\
\hline 18 & 60 & Normal \\
\hline 19 & 60 & Normal \\
\hline 20 & 56 & Normal \\
\hline 21 & 51 & Normal \\
\hline 22 & 72 & High \\
\hline 23 & 28 & Low \\
\hline 25 & 61 & Normal \\
\hline 26 & 46 & Normal \\
\hline 27 & 44 & Normal \\
\hline 28 & 50 & Normal \\
\hline 29 & 43 & Normal \\
\hline 30 & 79 & High \\
\hline
\end{tabular}

Source: Authors using the data provided by the Center for Medical and Sociological Research, Saratov.

From Table 1, it can be seen that no employee has a very high and very low level of empathy that is why, in our sample, there are only three levels: high, normal, and low. Moreover, 63\% of employees have a normal (average) level of empathy. The distribution of employees by the level of empathy development is presented below in Figure 1.

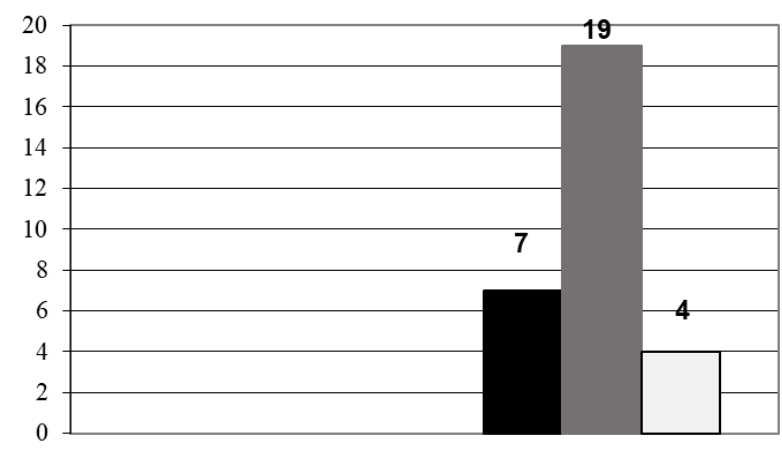

aigh level

normal level

$\square$ low level

Figure 1: Distribution of Employees by the Level of Empathy Development

(Source: Authors using the data provided by the Center for Medical and Sociological Research, Saratov).

Thus, we can interpret that the employees of the center try to show attention and delicacy in interpersonal relations; they tend to judge others by their actions, emotional manifestations are mostly under control.

The diagnostic results obtained by the communicative and organizational inclinations (COI) method are presented in Table 2. As can be seen from the presented results, the majority of employees have a relatively high level of communication skills, but only 6 people have organizational skills.

Table 2: The Level of Communicative and Organizational Skills Development among the Employees of the Center

\begin{tabular}{ccccc}
\hline $\begin{array}{c}\text { № / } \\
\text { code }\end{array}$ & $\begin{array}{c}\text { Communicative } \\
\text { skills }\end{array}$ & Level & $\begin{array}{c}\text { Organizational } \\
\text { skills }\end{array}$ & Level \\
\hline 1 & 0,47 & Below average & 0,36 & Low \\
\hline 2 & 0,29 & Low & 0,24 & Low \\
\hline 3 & 0,69 & High & 0,58 & Below average \\
\hline 4 & 0,62 & Average & 0,47 & Low \\
\hline
\end{tabular}




\begin{tabular}{ccccc}
\hline 5 & 0,61 & Average & 0,35 & Low \\
\hline 6 & 0,68 & High & 0,69 & Average \\
\hline 7 & 0,58 & Average & 0,41 & Low \\
\hline 8 & 0,69 & High & 0,58 & Below average \\
\hline 9 & 0,32 & Low & 0,59 & Below average \\
\hline 10 & 0,74 & High & 0,49 & Low \\
\hline 11 & 0,73 & High & 0,79 & High \\
\hline 12 & 0,31 & Low & 0,31 & Low \\
\hline 13 & 0,74 & High & 0,56 & Below average \\
\hline 14 & 0,29 & Below average & 0,39 & Low \\
\hline 15 & 0,79 & High & 0,58 & Below average \\
\hline 16 & 0,57 & Average & 0,69 & Average \\
\hline 17 & 0,37 & Low & 0,36 & Low \\
\hline 18 & 0,65 & Average & 0,84 & Very high \\
\hline 19 & 0,74 & High & 0,57 & Below average \\
\hline 20 & 0,56 & Average & 0,48 & Low \\
\hline 21 & 0,59 & Average & 0,67 & Average \\
\hline 22 & 0,73 & High & 0,71 & High \\
\hline 23 & 0,81 & Very high & 0,79 & High \\
\hline 24 & 0,71 & High & 0,88 & Very high \\
\hline 25 & 0,36 & Low & 0,41 & Low \\
\hline 26 & 0,84 & Very high & 0,74 & High \\
\hline 27 & 0,45 & Below average & 0,46 & Low \\
\hline 28 & 0,81 & Very high & 0,69 & Average \\
\hline 29 & 0,79 & Very high & 0,56 & Below average \\
\hline 30 & 0,62 & Average & 0,59 & Below average \\
\hline
\end{tabular}

Source: Authors using the data provided by the Center for Medical and Sociological Research, Saratov

The data obtained in the framework of the study clearly show the work capacity of this team. With competent management and rational distribution of labor duties, he is ready to successfully solve the tasks as it is evidenced in Figure 2.

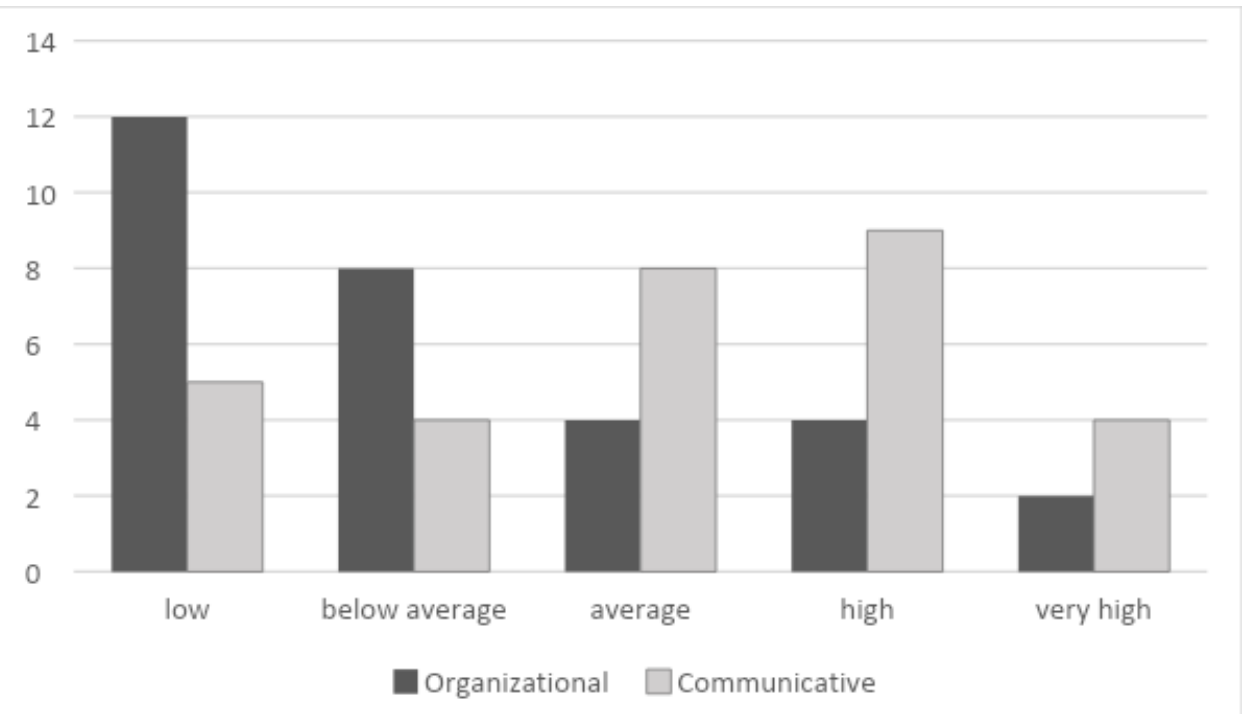

Figure 2: Distribution of Employees by the Level of Communicative and Organizational Skills

Source: Authors using the data provided by the Center for Medical and Sociological Research, Saratov

An interesting, consistent pattern is revealed in this figure, showing dependence between the development level of organizational abilities and communicative ones. It is difficult to imagine the work of a team consisting entirely of active organizers. This type of personality does not always have the proper patience and scrupulousness in the performance of 
the duties. Therefore, a skillful combination of activity and sociability of some people with patience and inner composure, aimed at the gradual implementation of the instructions of others, brings success in the teamwork.

The next stage of the study is aimed at studying the parameters of interpersonal communication. Let us turn to the results obtained by the standardized self-report on the features of interpersonal communication. The results are presented in Table 3.

Table 3: Average Parameters of Interpersonal Communication

\begin{tabular}{ll}
\hline Parameters of interpersonal communication & \multicolumn{1}{c}{$\begin{array}{l}\text { Average } \\
\text { parameters } \\
\text { (from 0 to10) }\end{array}$} \\
\hline satisfaction - dissatisfaction with one's relationship with others & 12 \\
\hline with what categories of persons and to what extent this satisfaction is manifested & Colleagues -11 \\
\cline { 2 - 2 } & Clients -8 \\
\cline { 2 - 2 } $\begin{array}{l}\text { presence of difficulties of a procedural and dynamic nature in the process }-13 \\
\text { communication }\end{array}$ & 9 \\
\hline correspondence of existing relations with people in relation to others & 8 \\
\hline ability to effectively build relationships with other people & 11 \\
\hline the attitude from others according to the criterion of understanding - misunderstanding & 10 \\
\hline confidence - uncertainty in relationships with people & 9 \\
\hline $\begin{array}{l}\text { subjective assessment of the causes of difficulties in communication (in oneself - in a } \\
\text { partner) }\end{array}$ & In oneself -11 \\
\end{tabular}

Source: Authors using the data provided by the Center for Medical and Sociological Research, Saratov.

After analyzing the test results, typical difficulties of interpersonal communication were identified, and 12 people were selected. Of these, 4 employees have a low level of empathy, 8 employees have a below-average level of communication development. All selected employees have low organizational skills. All of them note dissatisfaction with their relationships with others, insecurity in relationships, inability to build their relationships with other people effectively,

Based on the study results, a socio-psychological training was organized aimed at improving the communicative activity of social workers having difficulties with interpersonal and professional contacts. It goes in line with the ideas expressed by D. K. Davletkaliev et al. (2015), U. V. Trokhirova and E. V. Zimina (2015), S. M. Richardson and T. M. Yates

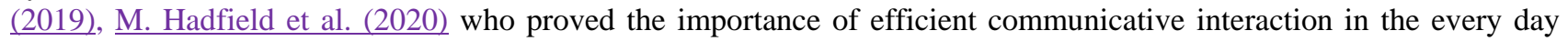
professional activities of social work specialists.

Training of the group of employees was done in accordance with the psychological specifics of the difficulties appearing in their interpersonal interaction as was stated by many scholars in the previous researches (Sommerfeld, 2014; Valeyeva et al., 2016; Mametyeva et al., 2018; Garrett, 2020; Miller et al., 2020; Stepney \&Metteri, 2020; Reed et al., 2020), dealing with various forms and peculiarities of interaction of social workers in and with communities. Thus, it pursued the following aims:

- Development of the focus on socio-psychological activity;

- Correction and formation of some socio-psychological communicative skills;

- Development of participants' ability to empathy;

- Increasing sensitivity to non-verbal forms of contact, decoding non-verbal ways of communicating with people.

As evidenced by the data of diagnostic procedures carried out after the end of the training, and the data of self-reports characterizing the changes in the self-attitude of the subjects, the level of awareness of their problems in the process of interaction with others, mastery of some tactics of behavior, communication training organized according to the developed program, gave a positive result.

\section{CONCLUSION}

Summing up the work done, it is necessary to note the identification of the problems associated with the communicative competence of service employees, which is an integral component of social activities. The primary vector of successful work of social services is to carry out preventive work to establish communication links within the team and to smooth out the consequences of communication with the recipients of social services through training courses aimed at improving the culture of mutual interaction.

In the framework of this work, trainings conducted according to the intended program gave the psychological and practical influence on the personality of people and their actual behavior. The main effect of the impact was expressed in 
the increase of the overall psychological culture in relations with others, focusing on others, desire to to build relationships with people, change oneself productively.

It was explicitly manifested in the increase in the level of self-knowledge, awareness of one'sshortcomings in interacting with others, adequacy of the perception and understanding of another person, development of empathy level, sensitivity to non-verbal means of communication, and formation of new communicative skills.

A practical orientation of this study showed the importance of the influence of active teaching methods on interpersonal communication and made it possible to develop and many practically effective methods that allow increasing the effectiveness of interaction with others in their professional activities. It should be noted that socio-psychological training and its results do not fit into the time frame even within a continuous training session. This is a long process, the effectiveness of which is revealed in the course of the real-life of people. The laboratory cycle of active learning is only a starting mechanism in itself that discloses the potential of the socio-psychological learning ability of a person, further verified by the practice of his/her actual actions.

A comprehensive solution to these problems acts as an orientation aim of the socio-psychological training. Moreover, the variety of active group methods used at the laboratory stage expands the learner's perceptual field in the subsequent contacts with real life events, increases the resources of interpersonal inventiveness, communicative competence and professional success in general.

This program will contribute to the formation of professional and personal qualities, communicative skills of a specialist as well as awareness of one's values, contributing to the development of interest to the chosen profession and professional success.

\section{LIMITATION AND STUDY FORWARD}

The present study was geographically limited to the Russian Federation only. However, the discussed issues are of high importance worldwide. Thus, the authors plan to develop their methodology further and conduct a comparative three or four country studyon communicative competence features of social sphere specialists.

\section{ACKNOWLEDGEMNT}

We are grateful to the head and staff of the Center for Medical and Sociological Research in Saratov (Russia) for valuable collaboration during our research study.

\section{AUTHORS CONTRIBUTION}

Aleksandra S. Shcheglova was writing the introduction part of the paper, Tatyana E. Demidova was doing literature review on the studied issue, Anna. G. Akhtyan and Nataliya A. Bereza were analysing the material for Results and Discussion section, Alfiya A. Salkhenova contributed extensively to the overall methodology and conclusion parts.

\section{REFERENCES}

1. Anastas, J. W. (2014). The science of social work and its relationship to social work practice. Research on Social Work Practice, 24 (5), 571-580. https://doi.org/10.1177/1049731513511335

2. Aulwin, S. (1985). Structure in Thought and Feeling (PLE: Emotion). London: Psychology Press.

3. Brekke, J. S. (2014). A Science of social work, and social work as an integrative scientific discipline: Have we gone too far, or not far enough? Research on Social Work Practice, 24 (5), 517523.https://doi.org/10.1177/1049731513511994

4. Bryant, L., \& Williams, C. (2020). Place and space in social work. Qualitative Social Work, 19(3), 321-336. https://doi.org/10.1177/1473325020918794

5. Caras, A., \&Sandu, A. (2014). The Role of supervision in professional development of social work specialists. Journal of Social Work Practice, 28(1), 75-94.https://doi.org/10.1080/02650533.2012.763024

6. Chigisheva, O., Soltovets, E., \&Bondarenko, A. (2017). Functional foreign language literacy for global research career development: Analysis of standardized open-ended interview responses. XLinguae, 10(4), 138-153. https://doi.org/10.18355/XL.2017.10.04.12

7. Chigisheva, O. (2018). Functional literacy: Terminological ambiguity in the worldwide educational context. Astra Salvensis, 6, 963-970.

8. Chigisheva, O. P., Soltovets, E. M., \&Bondarenko, A. V. (2016). The role of formal and informal components in foreign language functional literacy enhancement of SFEDU faculty members: survey results. International Journal of Economics and Education, 2(3), 7-21.

9. Davletkaliev, D. K., Zueva, N. K., Lebedeva, N. V., Mkrtumova, I. V., \&Timofeeva, O. (2015). Professional competence development of the social work specialists in the period of study in the system of additional education. International Education Studies, 8(6), 176-183. https://doi.org/10.5539/ies.v8n6p176

10. Draskovic, M., Milica, D., Mladen, I., \&Chigisheva, O. (2017). Preference of institutional changes in social and economic development. Journal of International Studies, 10(2), 318-328. https://doi.org/10.14254/2071$\underline{8330.2017 / 10-2 / 22}$ 
11. Egorychev, A. M., Fomina, S. N., Rostovskaya, T. K., Kozlovskaya, S. N., Mardakhaev, L. V., Starovojtova, L. I., Scheglova, A. S., Shimanovskaya, Y. V., Sizikova, V. V., Anikeeva, O. A., Firsov, M. V., Kvitkovskaya, A. A., Birch, N. A., Knyazkova, E. A., Akhtyan, A. G., \&Karpunina, A. V. (2019). Vocational education in Russia: challenges, condition, development directions: collective monograph. Moscow: Publishing House of the Russian State Social University.

12. Egorychev, A. M., Mardakhaev, L. V., Sizikova, V. V., Volenko, O. I., Akhtyan, A. G., Varlamova, E. Yu., \&Knyazkova, E. A.(2018). Deontological culture of social sphere specialists and the need for its formation. International Journal of Civil Engineering and Technology, 9(11), 1781-1788.

13. Finzi-Dottan, R., \&Kormosh, M.B. (2016). Social workers in Israel: compassion, fatigue, and spillover into married life. Journal of Social Service Research, $42 \quad$ (5), 703-717. https://doi.org/10.1080/01488376.2016.1147515

14. Firsov, M. V., \&Studenova, E. G. (Eds.). (2016). Technology of social work: textbook. Moscow: KNORUS.

15. Garanina, Zh. G., Andronova, N. V., Lashmaykina, L. I., Maltseva, O. E., \&Polyakov, O. E. (2017). The structural model of future employees? Personal and professional self-development. Integration of Education, 21(4), 596-608. https://doi.org/10.15507/1991-9468.089.021.201704.596-608

16. Garrett, P. M. (2020). Looking east: (Re-)creating a social work 'industry' in the People's Republic of China. Critical Social Policy, 40(3), 410-429. https://doi.org/10.1177/0261018319853492

17. Gorlova, N. I., Troska, Z. A., Starovojtova, L. I., Demidova, T. E., Akhtyan, A. G., \&Shcheglova, A. S. (2019). Restoration volunteering as a social phenomenon of modern history. Academic Journal of Interdisciplinary Studies, 8(2), 147-154.https://doi.org/10.2478/ajis-2019-0026

18. Hadfield, M., Ruch, G., Winter, K., Cree, V., \& Morrison, F. (2020). Social workers' reflexive understandings of their "everyday" communications with children. Child and Family Social Work, 25(2), 469-477. https://doi.org/10.1111/cfs.12703

19. Harris, J., Borodkina, O., Brodtkorb, E., Evans, T., Kessl, F., Schnurr, S., \&Slettebø, T. (2015). International travelling knowledge in social work: an analytical framework. European Journal of Social Work, 18 (4), 481494. https://doi.org/10.1080/13691457.2014.949633

20. Holostova, E. I. (2007). Professionalism in social work: textbook. Moscow.

21. Huber, G. P. (1990). A Theory of the Effects of Advanced Information Technologies on Organizational Design, Intelligence, and Decision Making. Academy of Management Review, 15(1), 4771.https://doi.org/10.5465/amr.1990.4308227

22. Kholostovoy, E. I., \&Kononova, L. I. (Eds.). (2019). Technology of social work: a textbook for bachelors. Moscow: Yurayt Publishing House.

23. Knoop, T., \& Meyer, T. (2020). The effect of social work services on a self-reported functional outcome. Research on Social Work Practice, 30(5), 564-575. https://doi.org/10.1177/1049731520906607

24. Komarova, E. I., \&Voitenko, A. I. (Eds.). (2001). Management of social work: textbook. allowance for students. Moscow: VLADOS.

25. Mametyeva, O. S., Burilkina, S. A., \&Kaminskii, A. S. (2018). Formation in social sphere specialists their preparedness to implement social technologies in work with families of various types. PerspektivyNauki $i$ Obrazovania, 36(6), 74-84. https://doi.org/10.32744/pse.2018.6.8

26. McKee, K. B., Richardson, K. B., Hinton, M., \& Lamb, L. F. (2009). Applied Public Relations: Cases in Stakeholder Management. New York: Routledge. https://doi.org/10.4324/9780203871546

27. Medvedev, G. P. (2018). Philosophy of social work. Textbook manual for universities (undergraduate level). Moscow: KnoRus.

28. Milanovic, B. (2017). Income, Inequality and Poverty During the Transition. World Bank.

29. Miller, J., Lee, J., Shalash, N., \&Poklembova, Z. (2020). Self-compassion among social workers. Journal of Social Work, 20(4), 448-462. https://doi.org/10.1177/1468017319829404

30. Negahban, M.B. (2020). The study of scientific map and thematic structure of social work. Asian Social Work and Policy Review, 14(2), 99-106. https://doi.org/10.1111/aswp.12197

31. Pavlenok, P. D. (2017). Theory, history and methods of social work. Moscow: Dashkov and K.

32. Reed, S., Evans, E. J., \&Hooyman, N. (2020). Social Work: Leading the Move Upstream to Improve the Nation's Health. Health \& Social Work, 45(2), 77-79.https://doi.org/10.1093/hsw/hlaa006

33. Richardson, S. M., \& Yates, T. M. (2019). Characterizing communication between transition-aged foster youth and their social workers.Journal of Social Work, 19(3), 372-396. https://doi.org/10.1177/1468017318762093

34. Rogov, E. I. (1999). Handbook of the Practical Psychologist: Textbook. In 2 books. Book 2. Moscow: VLADOS.

35. Sadzaglishvili, S., Akobia, N., Shatberashvili, N., \&Gigineishvili, K. (2020). A social work intervention's effects on the improvement of school culture. SocialniPrace, 20(1), 45-60.

36. Santos, C. P. C. D., Valduga, T., \& Ferreira, J. (2020). Social work in the web of social protection: Contexts and alternatives. International Social Work, 63(3), 291-305. https://doi.org/10.1177/0020872818788924

37. Sidorenko, E. V. (2008). Communication skills training in business interaction. St. Petersburg: Speech.

38. Sommerfeld, P. (2014). Social work as an action science: a perspective from Europe. Research on Social Work Practice, 24 (5), 586-600. https://doi.org/10.1177/1049731514538523 
39. Stepney, P., \&Metteri, A. (2020). Social work and empowering communities. SocialniPrace, 20(1), 2-6.

40. Straussner, S. L. A., \&Senreich, E. (2020). Productive aging in the social work profession: a comparison of licensed workers 60 years and older with their younger counterparts. Clinical Social Work Journal, 48(2),196210. https://doi.org/10.1007/s10615-020-00747-y

41. Strelkova, I. E. (1967). Psychology of friendship of teenage schoolchildren: PhD thesis abstract. Moscow: Moscow State Pedagogical Institute named after V. I. Lenin.

42. Tarman, B., \&Chigisheva, O. (2017). Transformation of educational policy, theory and practice in post-soviet social studies education. Journal of Social Studies Education Research, 8(2), I-IV.

43. Taube, V., \&Bördlein, C. (2020). Social work research in German-speaking countries. Research on Social Work Practice, 30(5), 475-478. https://doi.org/10.1177/1049731520904132

44. Tilbury, C., Hughes, M., Bigby, C., Fisher, M., \& Vogel, L. (2017). A comparative study of Australian social work research. British Journal of Social Work, 47 (8), 2217-2237. https://doi.org/10.1093/bjsw/bcw135

45. Topchy, L. V. (2015). Methodological problems of the theory of social work: a textbook. Moscow: Russian State Social University.

46. Trokhirova, U. V., \&Zimina, E. V. (2015). Professionallzation of social works In the region: Problems and prospects (the case of Irkutsk region). SotsiologicheskieIssledovaniya, 6, 45-52.

47. van den Heuvel, W. J. A, Illsley, R., Jamieson, A., \&Knipscheer, C. P. M. (Eds.). (1989). Opportunities and Challenges in an Ageing Society: "Proceedings of the colloquium 'Opportunities and Challenges in an Ageing Society', Amsterdam, 26-28 October 1989. Amsterdam: North-Holland Publishing Co.

48. Valeyeva, N. S., Kupriyanov, R. V., Valeyeva, E. R., Nadeyeva, M. I., Guryanova, T. N., Yurtayeva, N. I., Kaysarova, Z. E., \&Safina, A. A. (2016). The managerial mechanism of social sphere future specialists' professional world view formation. International Review of Management and Marketing, 6(2), 135-141.

49. Wilson, T. E. (2020). Social work stories: situated views and larger visions in disciplinary scholarship and education. Social Work Education, 39(5), 572-583. https://doi.org/10.1080/02615479.2019.1703930

50. Zamaraeva, Z. P., \&Starovojtova, L. I. (2019). Professionalization of social education. CITIZE, 3(20). Retrieved from http://ma123.ru/ru/2019/06/3-замараева-старовойтова

51. Zamiralova, T. A., Akhtyan, A. G., Karpunina, A. V., Kvitkovskya, A. A., Knyazeva, O. O., \&Yagodina, N. V. (2019). State and municipal administration: Problems and prospects of development in modern Russia. EurAsian Journal of BioSciences, 13(2), 2211-2215.

52. Zanina, K. D., \&Akhtyan, A. G. (2018). Typology of personality and its practical application in the formation of social interactions. In Proceedings of the III All-Russian scientific and practical conference of graduate students (as part of the Science Week), April 16-20, 2018 (pp. 218-222). Moscow: Publishing House of the Russian State Social University. 